\title{
ASSESSMENT OF EUROCODE 5 CHARRING RATE CALCULATION METHODS
}

\author{
PAULO B. CACHIM ${ }^{1}$ and JEAN-MARC FRANSSEN ${ }^{2}$
}

\begin{abstract}
The basic hypothesis for the assessment of fire resistance of wood structures is that for temperatures above $300{ }^{\circ} \mathrm{C}$, wood is no longer able to sustain any load. Consequently, the determination of the location of the $300{ }^{\circ} \mathrm{C}$ isotherm, the charring depth, is decisive for the result of fire resistance calculation methods. Charring rate of wood is dependent of numerous factors, such as wood species (density, permeability or composition), moisture or direction of burning (along or across the grain).

Eurocode 5, Part 1-2, presents several methods for the calculation of fire resistance of timber structures that are divided into simplified and advanced. In this paper simplified and advanced methods are compared regarding the calculation of the charring depth. Finite element simulations have been performed, using the proposed wood properties of Eurocode 5 using finite element code SAFIR. The influence of parameters such as wood density, moisture or anisotropy has been investigated. The results obtained with finite element calculations were then compared with Eurocode 5 simplified models. Some inconsistencies between methods have been observed. This paper presents proposals to overcome some of the inconsistencies as well as to extend the applicability of the models.
\end{abstract}

\section{INTRODUTION}

Fire resistance of wooden members or structures is strongly dependent of the rate at which wood burns. Therefore, codes of practice such as Eurocode 5 Part 1-2 ${ }^{[1]}$, named in this paper as EC5, specify models for the calculation of the amount of charred wood after a certain period of time.

\footnotetext{
${ }^{1}$ Professor, University of Aveiro, Department of Civil Engineering, Aveiro, Portugal, email: pcachim@ua.pt.

${ }^{2}$ Professor, University of Liege, Department of Structural Engineering, Liege, Belgium, email: JM.Franssen@ulg.ac.be.
} 
Charred wood is bounded by the transition between the pyrolysis layer, the zone where thermal degradation of wood and char formation are actually occurring and the char layer, a zone of cracked charcoal that has no relevant strength or stiffness properties. This transition is usually considered to be located at the $300{ }^{\circ} \mathrm{C}$ isotherm, named the char-line. Charring depth is the distance between the outer surface of the original member and the position of the char-line. The speed at which charring depth advances in the material is called the charring rate and is an essential parameter for fire resistance of wooden structures because it allows the determination of the size of the residual section of wood. Charring rate of wood is dependent of numerous factors, such as wood species, density, moisture, permeability, composition, or direction of burning (along or across the grain). However, only some of these factors can be actually considered in practical applications.

EC5 allows the use of simplified and advanced methods for the calculation of the amount of charred wood. Simplified methods use the charring rate model that is based in the fact that, even if the evolution of charring depth with time is non-linear, in practice, due to its limited non-linearity, it can be considered as linear. This means that the charring rate can be considered independent of time. Advanced methods, use more sophisticated analysis and design procedures that supposedly lead to more accurate predictions of the fire behaviour of structures. The method proposed in EC5 is a conductive model based on thermal properties of wood that uses heat transfer equations for the determination of distribution of temperature within structural sections; this thermal calculation is then normally followed by a structural calculation taking into account the progressive degradation of mechanical properties for the evaluation of the behaviour of the structure.

The aim of the present work is to assess the results obtained by the charring rate and the conductive models of EC5. The study was carried out based on numerical finite element simulations using the finite element code SAFIR ${ }^{[2]}$, which is a special purpose finite element code, developed at University of Liege for studying structures subjected to fire. Influence of moisture and density was investigated. Some proposals for improvement the consistency between the different models of EC5 are also presented.

\section{EUROCODE 5 MODELS FOR CHARRING RATE AND THERMAL ANALYSIS}

EC5 allows the use of a conductive model based on the resolution, transient, heat transfer differential equation, incorporating thermal properties that vary with temperature for the calculation of thermal fields within structural elements. However, effects such as mass transfer within the elements or structure, reaction energy released inside the wood due to pyrolysis or degradation of material, cracking of charcoal, which increases the heat transfer in the char layer, are not accounted for. EC5 presents conductivity values for the char layer that are apparent in order to take into account increased heat transfer due to shrinkage cracks above about $500{ }^{\circ} \mathrm{C}$ that increase heat transfer due to convection and radiation. In addition, specific heat capacity values include the energy necessary to evaporate the water, which explains the presence of the peak between 99 and $120^{\circ} \mathrm{C}$.

Charring rate models use the charring rate concept to calculate the residual section of a wooden cross-section after a certain exposure to fire. EC5 allows the use of two different charring rates: the one-dimensional design charring rate under standard fire exposure, $\beta_{0}$, and the notional charring rate, $\beta_{\mathrm{n}}$. When using the one-dimensional charring rate, calculation of cross-sectional properties should be based on the actual charring depth including corner roundings. The use of the notional charring rate allows considering rectangular residual cross sections. In the current work the one-dimensional charring, $\beta_{0}$, rate will be considered and 
compared with the conductive model because this eliminates unnecessary complications linked to geometrical considerations and allows concentrating purely on the thermal models.

The charring rate values given in EC5 for softwoods and hardwoods are presented in Table 1. Charring rate values presented in EC5 are independent of density for softwoods with densities above $290 \mathrm{~kg} / \mathrm{m}^{3}$ and for hardwoods with densities above $450 \mathrm{~kg} / \mathrm{m}^{3}$. For hardwoods the charring rate varies linearly for densities between 290 and $450 \mathrm{~kg} / \mathrm{m}^{3}$.

Table 1. Charring rate of wood for simple models of EC5.

\begin{tabular}{llc}
\hline \hline Wood type & & $\boldsymbol{\beta}_{\mathbf{0}}$ \\
\hline \hline Softwood and beech & $\begin{array}{l}\text { Glued laminated timber with a characteristic density } \\
\text { of } \geq 290 \mathrm{~kg} / \mathrm{m}^{3}\end{array}$ & 0.65 \\
\cline { 2 - 3 } & $\begin{array}{l}\text { Solid timber with a characteristic density of } \geq 290 \\
\mathrm{~kg} / \mathrm{m}^{3}\end{array}$ & 0.65 \\
\hline Hardwood & $\begin{array}{l}\text { Solid or glued laminated hardwood with a } \\
\text { characteristic density of } 290 \mathrm{~kg} / \mathrm{m}^{3}\end{array}$ & 0.65 \\
\hline $\begin{array}{l}\text { Solid or glued laminated hardwood with a } \\
\text { characteristic density } \geq 450 \mathrm{~kg} / \mathrm{m}^{3}\end{array}$ & 0.50 \\
\hline
\end{tabular}

\section{INFLUENCE OF DENSITY}

The fact that the charring rate changes with wood density has been demonstrated by several authors from several countries ${ }^{[3-6]}$. However, this dependency is only marginally considered in the charring rate models of EC5 as shown in Table 1. Australian Standard AS $1720.4^{[7]}$ explicitly considers the effect of density on the charring rate and is consequently used here for comparison purposes. The dependence of charring rate with density is given in the Australian Standard by:

$$
\beta=0.4+\left(\frac{280}{\rho_{12}}\right)^{2}
$$

For calculations of charring depth using the conductive model, the coefficient of heat transfer by convection was considered as $9 \mathrm{~W} / \mathrm{m}^{2} \mathrm{~K}$ on unexposed surfaces and $25 \mathrm{~W} / \mathrm{m}^{2} \mathrm{~K}$ on surfaces heated with the standard time-temperature curve, according to Eurocode 1, Part 1-2 [8]. The surface emissivity of wood was taken as 0.8 . Thermal conductivity, specific heat capacity and density ratio were used with values defined in EC5. Moisture content of wood, $w$, was considered equal to 0.12 . Densities of $200,290,450,600,800$ and $1000 \mathrm{~kg} / \mathrm{m}^{3}$ were investigated. The evolution of charring depth with time for the different densities is shown in Fig. 1, where it is apparent that significant differences exist for different densities.

The curves showing the evolution of the charring depth with time present a slight convexity. The charring rate is the first derivative of the curves. Because of the nearly linear character of the curves average charring rates were calculated for 30 and 60 minutes (taken as the secant value from the origin). From here, the secant charring rate used for comparison purposes is the secant charring rate at 60 minutes. 


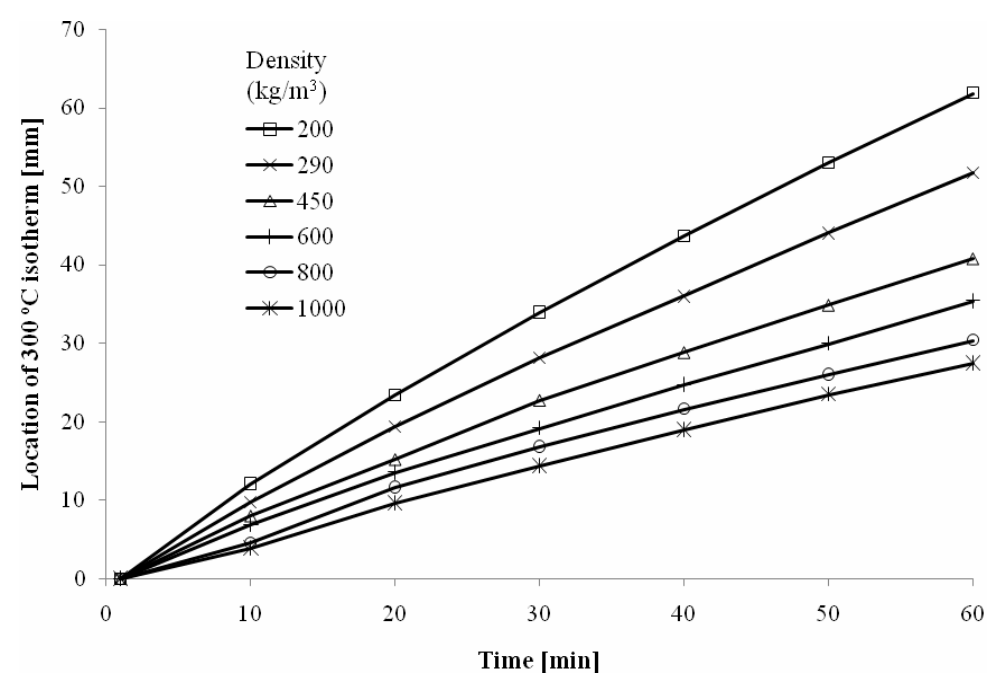

Fig. 1 - Evolution of charring depth with time for several densities.

Charring rate values calculated from Fig. 1 (see Table 2) are compared with the EC5 charring rate model for softwoods (EC5-SW) and hardwoods (EC5-HW), as well as with the Australian Standard, AS. Comparisons of the models show that for densities above $700 \mathrm{~kg} / \mathrm{m}^{3}$, typical of hardwoods, the Australian Standard, EC5-HW and conductive models give relative similar results. Below $600 \mathrm{~kg} / \mathrm{m}^{3}$, the models show significant differences, with the AS model being the one with highest charring rates. EC5-SW and conductive models show good agreement for $450 \mathrm{~kg} / \mathrm{m}^{3}$.

Table 2. Charring rates calculated with the EC5 conductive model ( $\mathrm{mm} / \mathrm{min})$.

\begin{tabular}{lcccccc}
\hline \hline & \multicolumn{6}{c}{ Density $\left[\mathrm{kg} / \mathrm{m}^{3}\right]$} \\
\cline { 2 - 6 } & 200 & 290 & 450 & 600 & 800 & 1000 \\
\hline \hline Charring rates at $60 \mathrm{~min}$ & 1.032 & 0.876 & 0.682 & 0.600 & 0.512 & 0.461 \\
\hline \hline
\end{tabular}

The potential regression curve that fits to the results of the conductive model reads:

$$
\beta_{\rho}=14.28 \rho_{12}^{-0.49}
$$

with a coefficient $r^{2}=0.998$. Numerical calculations are in agreement with the theory of heat transfer in materials with constant thermal properties that tells that the thermal propagation speed is proportional to the square root of thermal diffusivity:

$$
\beta \propto \sqrt{\frac{\lambda}{c \rho}}
$$

The results obtained numerically were further compared with experimental measurements performed previously at the University of Liege for tropical hardwoods ${ }^{[9]}$. Comparison of the conductive model with experimental data is presented in Fig. 2. EC5 charring rate value for hardwoods is also plotted. It can be observed that numerical results form an upper envelope of the experimental values. 


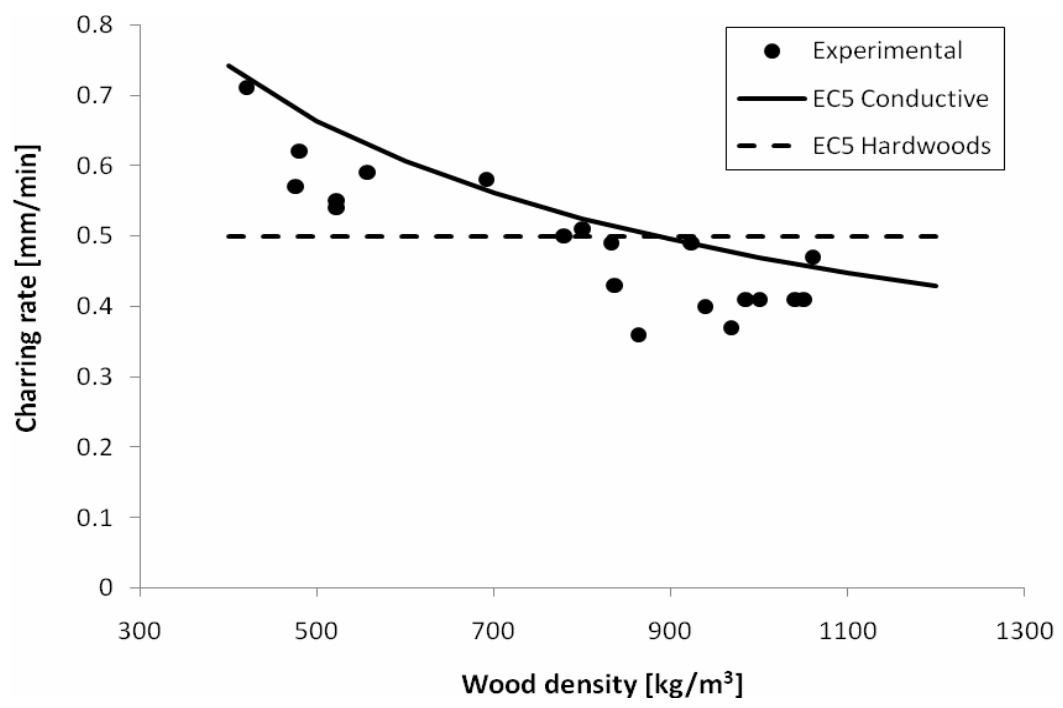

Fig. 2 - Relation between charring rate and water content.

\section{INFLUENCE OF MOISTURE}

The moisture content of wood has an influence on the thermal behaviour of timber. Heat conductivity of solid wood depends on moisture content as reported by several authors [10-13]. The effects of changes in conductivity of wood below $300{ }^{\circ} \mathrm{C}$ on the charring rate are not significant, but the evaporation of water consumes energy, changing the apparent specific heat curve of the composite wood-water material. Temperature in wood will remain approximately constant at about $100^{\circ} \mathrm{C}$ until all the water has been evaporated. Also density of wood is affected by the moisture content.

The charring rate of wood is proven to be dependent on moisture content as was demonstrated, for example by ${ }^{[3-4,14-15]}$.

Table 3. Density, moisture content and charring rate in numerical tests with modified conductive model.

\begin{tabular}{lcccc}
\hline \hline \multirow{2}{*}{ Case } & Dry density, $\rho_{0}$ & Water content & Density, $\rho_{w}$ & Charring rate \\
\cline { 2 - 5 } & {$\left[\mathrm{kg} / \mathrm{m}^{3}\right]$} & - & {$\left[\mathrm{kg} / \mathrm{m}^{3}\right]$} & {$[\mathrm{mm} / \mathrm{min}]$} \\
\hline $260-0$ & 260 & 0.00 & 260 & 0.881 \\
\hline $290-12$ & 260 & 0.12 & 290 & 0.876 \\
\hline $320-24$ & 260 & 0.24 & 320 & 0.841 \\
\hline $400-0$ & 400 & 0.00 & 400 & 0.702 \\
\hline $450-12$ & 400 & 0.12 & 450 & 0.682 \\
\hline $500-24$ & 400 & 0.24 & 500 & 0.671 \\
\hline $535-0$ & 535 & 0.00 & 535 & 0.609 \\
\hline $600-12$ & 535 & 0.12 & 600 & 0.600 \\
\hline $665-24$ & 535 & 0.24 & 665 & 0.590 \\
\hline $450-0$ & 450 & 0.00 & 450 & 0.662 \\
\hline \hline
\end{tabular}


EC5 specific heat and density ratio curves were defined for service class 1 , which means water content around 0.12. However, density ratio is defined in EC5 as a function of the water content indicating that this curve could be used also for water contents different from 0.12. Using this last assumption, calculation of the charring rate was performed for wood with different moisture contents. The base densities considered were 290, 450 and 600 $\mathrm{kg} / \mathrm{m}^{3}$ with $12 \%$ moisture. Thus, dry density of wood is 260,400 and $535 \mathrm{~kg} / \mathrm{m}^{3}$, respectively. Water contents are equal to 0.0, 0.12 and 0.24 (see Table 3 ). In addition, in order to compare two situations with the same overall density but with two different moisture contents, wood with dry density of $450 \mathrm{~kg} / \mathrm{m}^{3}$ was also considered (see Table 3 ). The calculated average charring rates after 60 minutes are presented in Table 3 . There is no significant difference between the results (differences in charring rate are less than $3 \%$ ) indicating that the conductive model proposed in EC5 is not really able to model the variations of the charring rate with moisture that have been reported in the literature.

\section{INFLUENCE OF ORTHOTROPY}

Wood is an anisotropic material with most of its properties substantially different when considered along the grain or across the grain. However, since the majority of the thermal calculations performed to evaluate the fire resistance of linear members are related to the transversal directions, little information regarding the longitudinal thermal properties of wood is available. However, there are situations, such as when $3 \mathrm{D}$ modelling of connections are performed, where along the grain thermal behaviour of wood is required.

Conductivity of wood along the grain has been reported to be in the range 1.5 to 2.8 times the conductivity across the grain, with the average value being around $2^{[15,16]}$.

Charring rate of wood along the grain is higher than across the grain ${ }^{[15,17]}$ with ratio between them ranging from $1.3^{[17]}$ to $2.0^{[15]}$.

Using the above considerations, modified conductive laws for wood have been tested.

It must be reminded that the properties of the char layer are those that mainly control the evolution of the charring rate (more than the properties of intact wood located ahead of the charring front). Two different approaches have been tried: (i) multiplication of the conductivity of the char layer above $500{ }^{\circ} \mathrm{C}$, by a constant factor $k_{1}$; and (ii) multiplication of the whole conductivity curve by a constant factor $k_{2}$, thus affecting the conductivity of wood and of the char layer. When referring to both parameters, the term $k$ parameter is used. Using the $\mathrm{k}$ parameter allows consideration of the conductivity across the grain proposed by EC5 to be modified to obtain a specific charring rate along the grain.

Table 4. Charring rate and conductivity normalised charring rate.

\begin{tabular}{lccccccc}
\hline \hline & & \multicolumn{6}{c}{ Multiplied values, $\mathrm{k}_{1}$ or $\mathrm{k}_{2}$} \\
\cline { 2 - 8 } & & 0.5 & 1.0 & 2.0 & 3.0 & 4.0 & 5.0 \\
\hline \hline $\begin{array}{l}\text { Charring rate } \\
{[\mathrm{mm} / \mathrm{min}]}\end{array}$ & $\mathrm{k}_{1}$ & 0.502 & 0.682 & 0.981 & 1.182 & 1.351 & 1.512 \\
\cline { 2 - 8 } $\begin{array}{l}\text { Conductivity } \\
\text { normalised charring } \\
\text { rate }\end{array}$ & $\mathrm{k}_{2}$ & 0.551 & 0.682 & 0.909 & 1.071 & 1.191 & 1.313 \\
\cline { 2 - 8 } & $\mathrm{k}_{1}$ & 0.797 & 1.000 & 1.319 & 1.551 & 1.725 & 1.899 \\
\hline
\end{tabular}


Wood with density of $450 \mathrm{~kg} / \mathrm{m}^{3}$ and 0.12 moisture was considered in the simulations. Values of the average charring rate at 60 minutes are shown for several values of the $k$ parameter in Table 4.

Conductivity normalised charring rate, $\beta_{z, \lambda}$, was defined in this study as the ratio between the charring rate at a specific $k$, and the charring rate obtained with EC5 conductivity $(k=1)$. The conductivity normalised charring rate is the ratio between along and across the grain charring rate. The conductivity normalised charring rate values are shown in Table 4. The results are relatively close, which shows that, as expected, conductivity of wood (below $300^{\circ} \mathrm{C}$ ) has little influence for the determination of the charring rate.

An exponential curve was fitted to the results, and the relation between $\beta_{z}$ and $k_{l}$ can be expressed by the regression equation:

$$
\beta_{z, \lambda}=k_{1}^{0.4}
$$

while the relation between $k_{2}$ and calculated $\beta_{z, \lambda}$, is given by the regression equation:

$$
\beta_{z, \lambda}=k_{2}^{0.47}
$$

There is no information in EC5 related to the charring rate or conductivity along the grain. Because the conductivity of wood at room temperature is also dependent on grain direction it seems logical to multiply the whole conductivity curve of wood defined in EC5. Modelling orthotropic behaviour of wood at high temperatures can be carried out by multiplying the conductivity across the grain by a factor $k_{\lambda}$, defined by:

$$
k_{\lambda}=\left(\beta_{/ /} / \beta_{\perp}\right)^{2}
$$

where $\beta_{/ /}$is the along the grain required charring rate and $\beta_{\perp}$ is the usual across the grain charring rate.

\section{POSSIBLE MODEL IMPROVEMENTS}

\subsection{Conductive model}

The effect of moisture when using the conductive model can be taken into account using a modified heat capacity curve that depends of moisture. The modified conductive model changes the proposed values for specific heat capacity based on the assumption that the heat capacity of wood with a water content $w, \mathrm{c}_{\mathrm{w}}$, is given by equation (10) ${ }^{[16]}$, in which the effect due to wood-water bond was neglected, and the liquid water specific heat capacity is $4190 \mathrm{~J} / \mathrm{kgK}$. It was further considered that specific heat values proposed by EC5 (see column 3 in Table 5) include $12 \%$ water. Equation (10) was then used to calculate the heat capacity of dry wood, $c_{0}$ (see column 4 in Table 5).

$$
c_{w}=\frac{c_{0}+4190 w}{1+w}[\mathrm{~J} / \mathrm{kgK}]
$$

The new expression for the moisture dependent specific heat (see column 5 in Table 5), was based on the following considerations: (i) from 20 to $99^{\circ} \mathrm{C}$, equation (10) is used as such, with the appropriate value for the dry wood $c_{0}$; (ii) from $120^{\circ} \mathrm{C}$ and beyond, it is assumed that the heat capacity given by EC5 is of dry wood; and (iii) from 99 to $120^{\circ} \mathrm{C}$, the term that multiplies $w$ was adapted in order to make the contribution linked to evaporation proportional to the water content. The factor that multiplies the water content in column 5 of Table 5, for temperatures between 99 and $120^{\circ} \mathrm{C}$, can be approximately obtained by summing, on one hand, the specific heat capacity of liquid water with, on the other hand, the energy consumed in water evaporation $(2250 \mathrm{~kJ} / \mathrm{kg})$ divided by the temperature interval $\left(21^{\circ} \mathrm{C}\right)$. The modified specific heat curve multiplied by the density ratio for 0,12 and $24 \%$ moisture can be observed in Fig. 3. 
Table 5. Modified thermal parameters to account for the effect of water content

\begin{tabular}{ccccc}
\hline \hline Temperature & $\begin{array}{c}\text { Density } \\
\text { ratio, } G\end{array}$ & $\begin{array}{c}\text { Specific heat } \\
\text { capacity of wood } \\
(\text { EC5) }\end{array}$ & $\begin{array}{c}\text { Specific heat } \\
\text { capacity of dry } \\
\text { wood, } c_{0}\end{array}$ & $\begin{array}{c}\text { Specific heat capacity } \\
\text { of wood with water, } \\
c_{w}\end{array}$ \\
\hline \hline${ }^{\circ} \mathrm{C}$ & - & {$[\mathrm{J} / \mathrm{kgK}]$} & {$[\mathrm{J} / \mathrm{kgK}]$} & {$[\mathrm{J} / \mathrm{kgK}]$} \\
\hline \hline$(1)$ & $(2)$ & $(3)$ & $(4)$ & $(5)$ \\
\hline \hline 20 & $1+\mathrm{w}$ & 1530 & 1210 & $(1210+4190 w) / G$ \\
\hline 99 & $1+\mathrm{w}$ & 1770 & 1480 & $(1480+4190 w) / G$ \\
\hline 99 & $1+\mathrm{w}$ & 13600 & 1480 & $(1480+114600 w) / G$ \\
\hline 120 & 1.00 & 13580 & 2120 & $(2120+95500 w) / G$ \\
\hline 120 & 1.00 & 2120 & 2120 & $2120 / G$ \\
\hline 200 & 1.00 & 2000 & 2000 & $2000 / G$ \\
\hline \hline
\end{tabular}



Fig. 3 - Modified specific heat capacity multiplied by $G$ for different water contents.

The influence of the water content on the charring rate of wood was recalculated for the same densities and moisture as previously analysed using the conductive model with the modified properties. The relation between charring rate and moisture for all cases is shown in Fig. 4.

The differences between the different charring rates are now much bigger: 11 to $14 \%$ reduction of the charring rate is observed when the moisture changes from 12 to $24 \%$, and 22 to $26 \%$ increase if the moisture changes from 12 to $0 \%$. It can also be observed that the change of the water content (from case 400-0 to 450-12) produces a bigger variation of the charring rate than the corresponding change in density (from case 400-0 to 450-0).

A moisture normalised charring rate, $\beta_{z, w}$, is defined here as the ratio between the charring rate at a specific water content and the charring rate at $w=0.12$, for the same dry wood density. The relation between the moisture normalised charring rate and the water content was obtained by regression analysis as being

$$
\beta_{z, w}=\left(\frac{1.12}{1+w}\right)^{1.5}
$$


With the moisture normalised charring rate it is possible to obtain the charring rate at any water content, in the range 0 to 0.24 , from the charring rate of wood with $w=0.12$, independently of wood density.

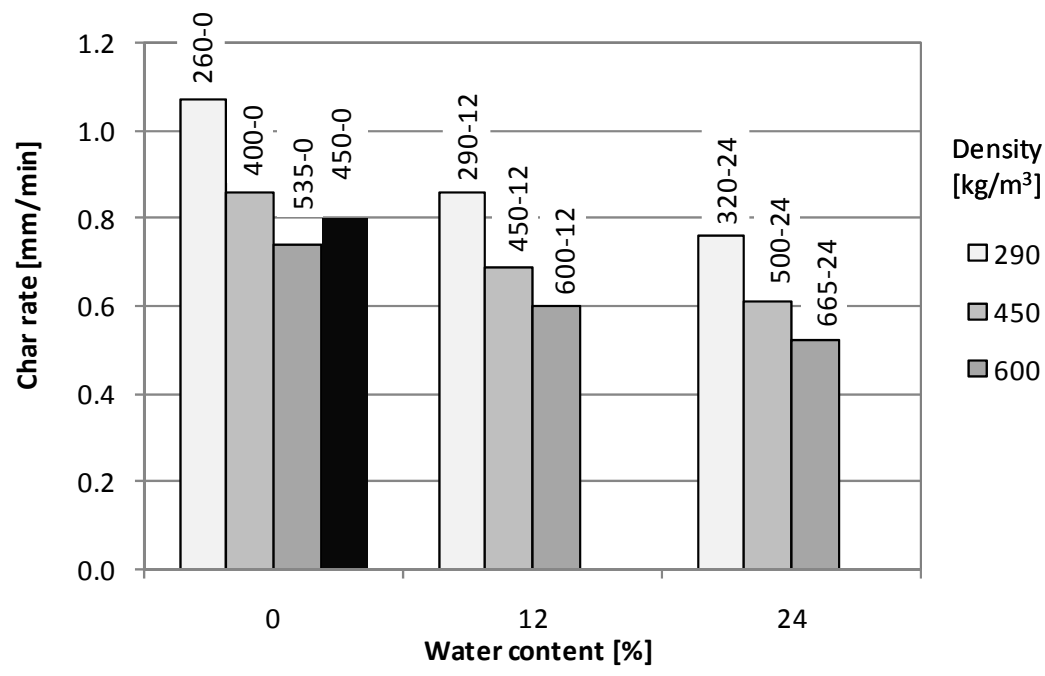

Fig. 4 - Relation between charring rate and water content.

\subsection{Charring rate model}

The charring rate values proposed by EC5 are independent of density for softwoods and show only a small dependence of density for hardwoods with low densities. Additionally, the charring rate values don't show any dependence of moisture. Therefore, there is some inconsistency between the results of the charring rate model and that of the conductive model. To reduce the differences between the charring rate and the conductive models of EC5 a modified charring rate model is proposed. The proposal consists in modify the basic charring rate calculated for wood with 0.12 moisture and density of $450 \mathrm{~kg} / \mathrm{m}^{3}, \beta_{450,12}$, by multiplying it by two factors: one that depends of wood density and other that depends of moisture.

The density term is derived from the results obtained from the numerical analysis. In fact, this correction term already exists in EC5 for panels and a similar expression also existed pre-standard version of EC5 for softwood densities below $290 \mathrm{~kg} / \mathrm{m}^{3}$.

For moisture, results of the modified conductive model, see Equation (11), were used to calculate the modification factor.

The charring rate, $\beta_{\rho, w}$, for wood with moisture content, $w$, and density at $12 \%$ moisture, $\rho_{12}$, can thus be obtained from $\beta_{450,12}$ as:

$$
\begin{aligned}
& \beta_{\rho, w}=k_{\rho} k_{w} \beta_{450,12} \\
& k_{\rho}=\sqrt{\frac{450}{\rho_{12}}} \\
& k_{w}=\left(\frac{1.12}{1+w}\right)^{1.5}
\end{aligned}
$$




\subsection{Comparison of conductive and charring rate models}

The results obtained with the possible improvement of both models are presented in Fig. 5. The evolution of the charring rate with wood density is plotted for water contents of 0 , 12 and $24 \%$, for both the charring rate (CR) and conductive (CO) models. With suggested improvements more coherent charring rate values are obtained together with increased consistency between conductive and charring rate models.

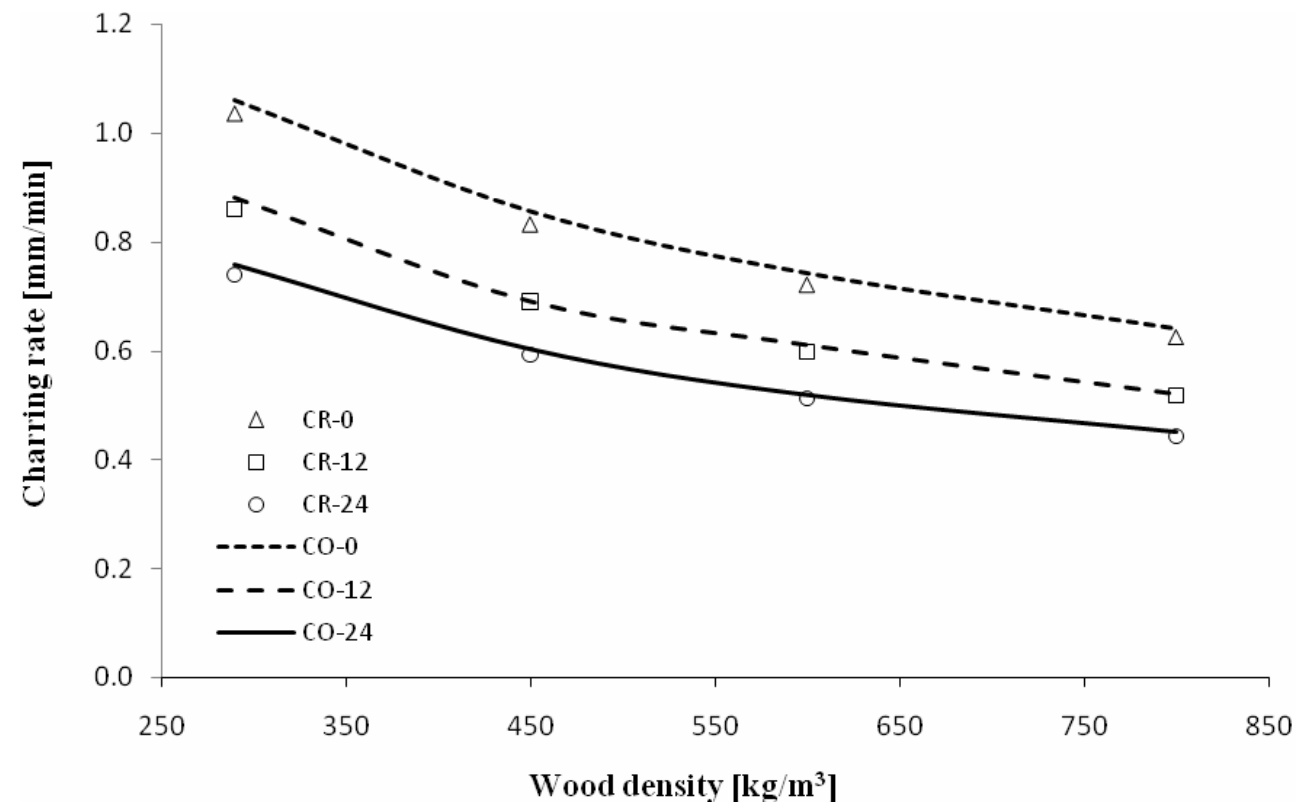

Fig. 5 - Comparison of proposed modified models.

\section{CONCLUSIONS}

A charring rate and a conductive model are presented in EC5 to calculate fire resistance of structures. Both models have some limitations, but most important, they have some inconsistencies. This paper presents proposals to overcome some of the inconsistencies as well as to extend the applicability of the models.

Material thermal properties presented in EC5 are extended to model orthotropic behaviour with a specified longitudinal charring rate by changing the wood conductivity. In addition, different moisture contents can also be considered by using a modified specific heat capacity curve.

An expression to calculate the charring rate as a function of density and moisture content has been proposed for the charring rate model that is compatible with the conductive model.

\section{REFERENCES}

[1] EN 1995-1-2:2004. Eurocode 5: Design of timber structures - Part 1-2: General Structural fire design. CEN, 2004. 
[2] Franssen J-M. SAFIR. A Thermal/Structural Program Modelling Structures under Fire, Engineering Journal, A.I.S.C., 2005: 42 (3), pp. 143-158.

[3] White RH, Erik V, Nordheim EV. Charring rate of wood for ASTM E 119 fire exposure. Fire Technology. 1992: 28 (1), pp. 5-30.

[4] White RH, Tran HC. Charring Rate of Wood Exposed to a Constant Heat Flux. Slovak Republic, s.n. Wood \& Fire Safety - 3rd Int.1 Scientific Conference, 1996, pp. 175-183.

[5] Njankouo JM, Dotreppe J-C, Franssen J-M. Experimental study of the charring rate of tropical hardwoods. Fire and Materials, 2004: 28, pp. 15-24, DOI: 10.1002/fam.831.

[6] König J, Walleij L. One-dimensional charring of timber exposed to standard and parametric fires in initially unprotected and postprotection situations. Swed Inst Wood Technol Res. 1999. Rapport I 9908029.

[7] Australia, Standards. AS 1720.4. Timber structures Part 4: fire resistance of structural timber members. North Sydney, Australia : Standards Australia, 1990.

[8] EN 1991-1-2:2002. Eurocode 1: Actions on structures - Part 1-2: General actions Actions on structures exposed to fire. CEN, 2002.

[9] Njankouo JM, Dotreppe J-C, Franssen, J-M. Fire resistance of timbers from tropical countries and comparison of experimental charring rates with various models. Construction and Building Materials. 2005: 19 (5), pp. 376-386.

[10] Gu H, Hunt JF. Two-dimensional finite element heat transfer model of softwood. Part III. Effect of misture content on thermal conductivity. [ed.] Society of Wood Science and Technology. Wood and Fiber Science. 2007: 39, pp. 159-166.

[11] FPL. Thermal conductive properties of wood, green or dry, from $-40^{\circ} \mathrm{TO}+100^{\circ} \mathrm{C}$ : A literature review. Madison, Wyscosin, USA : Forest Products Lab., 1977. Report FPL-9.

[12] Parker WJ. Development of a model for the heat release rate of wood - a status report.

U.S. Dep. Commerce. 1985. Report NBSIR 85-3163.

[13] Ragland KW, Aerts DJ. Properties of Wood for Combustion Analysis. Bioresource Technology. 1991: 37, pp. 161-168.

[14] Schaffer EL. Charring rate of selected woods transverse to grain. Forest Products Laboratory. Madison, wiscosin, USA : s.n., 1967. Research paper FPL 69.

[15] Hietaniemi J. A Probabilistic Approach to Wood Charring Rate. VTT Building and Transport. Finland : VTT Information Service, 2005. VTT Working Papers 31.

[16] FPL. Wood handbook. Wood as an engineered material. Madison, Wisconsin, USA : Forest Products Laboratory, 1999.

[17] Spearpoint MJ, Quintiere JG. Predicting the piloted ignition of wood in the cone calorimeter using an integral model - effect of species, grain orientation and heat flux. Fire Safety Journal. 2001: 36, pp. 391-415.

[18] Maciulaitis R, Lipinskas D, Lukosius K. Singularity and importance of determination of wood charring rate in fire investigation. Materials Science (MEDŽIAGOTYRA). 2006: 12, pp. 42-47. 